\title{
Tropospheric dry layers in the tropical western Pacific: comparisons of GPS radio occultation with multiple data sets
}

\author{
Therese Rieckh $^{1,2}$, Richard Anthes ${ }^{1}$, William Randel ${ }^{3}$, Shu-Peng Ho ${ }^{1}$, and Ulrich Foelsche ${ }^{4,2}$ \\ ${ }^{1}$ COSMIC Program Office, University Corporation for Atmospheric Research, Boulder, Colorado, USA \\ ${ }^{2}$ Wegener Center for Climate and Global Change, University of Graz, Graz, Austria \\ ${ }^{3}$ National Center for Atmospheric Research, Boulder, Colorado, USA \\ ${ }^{4}$ Institute for Geophysics, Astrophysics, and Meteorology/Institute of Physics, University of Graz, Austria \\ Correspondence to: Therese Rieckh (rieckh@ucar.edu)
}

Received: 29 July 2016 - Discussion started: 12 August 2016

Revised: 7 February 2017 - Accepted: 21 February 2017 - Published: 16 March 2017

\begin{abstract}
We use GPS radio occultation (RO) data to investigate the structure and temporal behavior of extremely dry, high-ozone tropospheric air in the tropical western $\mathrm{Pa}-$ cific during the 6-week period of the CONTRAST (CONvective TRansport of Active Species in the Tropics) experiment (January and February 2014). Our analyses are aimed at testing whether the RO method is capable of detecting these extremely dry layers and evaluating comparisons with in situ measurements, satellite observations, and model analyses. We use multiple data sources as comparisons, including CONTRAST research aircraft profiles, radiosonde profiles, AIRS (Atmospheric Infrared Sounder) satellite retrievals, and profiles extracted from the ERA (ERA-Interim reanalysis) and the GFS (US National Weather Service Global Forecast System) analyses, as well as MTSAT-2 satellite images. The independent and complementary radiosonde, aircraft, and RO data provide high vertical resolution observations of the dry layers. However, they all have limitations. The coverage of the radiosonde data is limited by having only a single station in this oceanic region; the aircraft data are limited in their temporal and spatial coverage; and the RO data are limited in their number and horizontal resolution over this period. However, nearby observations from the three types of data are highly consistent with each other and with the lower-vertical-resolution AIRS profiles. They are also consistent with the ERA and GFS data. We show that the RO data, used here for the first time to study this phenomenon, contribute significant information on the water vapor content and are capable of detecting layers in the tropics and subtropics with extremely low humidity (less than $10 \%$ ), indepen-
\end{abstract}

dent of the retrieval used to extract moisture information. Our results also verify the quality of the ERA and GFS data sets, giving confidence to the reanalyses and their use in diagnosing the full four-dimensional structure of the dry layers.

\section{Introduction}

Water vapor is the most important greenhouse gas in the troposphere, yet it is still the parameter with the highest uncertainty in weather and climate models. All current humidity observation techniques have limitations for analyzing global water vapor fields. For example, nadir-viewing satellite instruments (e.g., infrared (IR) or microwave (MW) sensors in space) are restricted by their low vertical resolution. IR sounders cannot observe within and under clouds. Radiosonde (RS) coverage is sparse or nonexistent over the open oceans. The radio occultation (RO) method does not suffer from these limitations, but water vapor information can only be derived by using a combination of RO data and information on temperature from another source (observations or model). In addition, RO observations have significant errors in the lower tropical troposphere under superrefraction conditions (Sokolovskiy, 2003).

A number of studies have shown good agreement between RO and RS moisture profiles (e.g., Kishore et al., 2011; Ho et al., 2010). These climatological studies focus on comparisons of RO with the global radiosonde network rather than extremely dry air (relative humidities less than $10 \%$ ). In this paper we study the ability of RO to measure extremely dry 
air in the tropics and subtropics, using for comparison highresolution aircraft profiles, radiosondes, IR satellite data, and the ERA (Berrisford et al., 2011).

Dry regions of the tropical and subtropical lower and mid-troposphere have a strong radiative impact on the climate system through their ability to radiate heat to space, preventing a "runaway greenhouse effect" (Pierrehumbert, 1995). Furthermore, they suppress deep convection (Brown and Zhang, 1997), are connected to cumulus congestus cloud top heights (Johnson et al., 1996), and affect boundary layer height and humidity (Parsons et al., 2000).

A number of studies have addressed the so-called dry intrusions in the normally moist mid- and lower troposphere of the tropical western Pacific. They were first investigated during TOGA-COARE, the Coupled Ocean-Atmosphere Response Experiment of the Tropical Ocean and Global Atmosphere project (Webster and Lukas, 1992). Mapes and Zuidema (1996), using soundings from TOGA-COARE, found that dry layers are generally too dry and not warm enough to be interpreted as adiabatic displacements within the tropics. Instead they suggest a subtropical origin. Dry layers typically have strong horizontal and vertical moisture gradients and sharp temperature inversions at the lower edge. They are stabilized by radiative cooling of the underlying moist air and heating of the dry air layer, thus inhibiting convection.

Cau et al. (2005) investigated the radiative impact and origin of dry intrusions observed by RS profiles in the tropical western Pacific using 40-year European Centre for MediumRange Weather Forecasts (ECMWF) reanalysis (ERA-40) wind and humidity data. They showed an outgoing longwave radiation increase of $3 \mathrm{~W} \mathrm{~m}^{-2}$ per $100 \mathrm{hPa}$ for dry intrusions with relative humidities of less than $20 \%$, almost independent of altitude. They pointed out the importance of the humidity distribution in a climate change scenario, considering that outgoing longwave radiation is more sensitive to small humidity perturbations in dry environments than in moist regions. Cau et al. (2005) also pointed out that cloud occurrence above or below the dry intrusion reduces the radiative impact. Furthermore, they used back trajectories to show that most dry events were associated with air descending from the extratropics. In their follow-up study, Cau et al. (2007) evaluated the origins of dry air in the tropics and subtropics using trajectory simulations for ERA-40 data for January 1993. They found four major transport mechanisms: (1) the descending branch of extratropical baroclinic waves; (2) the equatorial flank of the jet around subtropical anticyclones; (3) transport at regions of minimum subtropical jet strength via equatorward descent across the jet exit; and (4) dry air centering in the upper troposphere between regions of deep convection (see also Fig. 9 in Cau et al., 2007).

Regarding dry layer occurrence, Casey et al. (2009) created a 5-year climatology on dry layers between 600 and $400 \mathrm{hPa}$ over deep convective regions of the tropical oceans using AIRS (Atmospheric Infrared Sounder) data. Their re- sults show large spatial and seasonal variability for different ocean basins, pointing out the limits of applying case study trends to the whole basin.

Finally, Randel et al. (2016) performed a detailed comparison between aircraft measurements from the CONvective TRansport of Active Species in the Tropics (CONTRAST) experiment and GFS meteorological analyses, demonstrating that the analyses accurately capture the behavior of subtropical dry layers. A global climatology from GFS data shows that the dry layers are a ubiquitous feature of the subtropics, with maximum occurrence frequency in the winter hemisphere (linked to the strongest subtropical jets). The subtropical dry layers are highly correlated with enhanced ozone in both hemispheres, arguing for a source in the extratropical upper troposphere-lower stratosphere (UTLS).

A number of studies confirmed the capability of RO measurements to monitor the dry atmosphere (above around $8 \mathrm{~km}$; Foelsche et al., 2008, 2009) and for climate change detection (Leroy et al., 2006; Ho et al., 2009; Steiner et al., 2011; Ho et al., 2012). RO data feature inherent high accuracy and precision, high vertical resolution (100 to $200 \mathrm{~m}$ ), all-weather capability, and long-term stability (Anthes, 2011), making them highly valuable for studying a large number of atmospheric phenomena. Vergados et al. (2015) studied the spatial variability of relative humidity $(\mathrm{RH})$ from RO compared to ECMWF and MERRA (Modern-Era Retrospective analysis for Research and Applications), focusing on time-averaged seasonal behavior; these comparisons suggest an overall reliable behavior of RO-derived humidity fields. So far no study has focused on RO and extreme dryness $(\mathrm{RH}<10 \%)$.

$\mathrm{RH}$ is computed from measured water vapor pressure and saturation water vapor pressure over liquid or ice, depending on the temperature. The liquid formulation is used according to Murphy and Koop (2005).

This paper is structured as follows: in Sect. 2 we summarize the RO technique, the CONTRAST field campaign, and all other data sets we used. In Sect. 3 we show some example profile comparisons, explain features of dry layers, and discuss the contributions of a priori (first-guess) data and RO observations in the one-dimensional variational (1D-Var) retrieval. Section 4 focuses on one specific case in detail. In Sect. 5, we give a short overview of the results using all collocation pairs available. Section 6 discusses the global occurrence of dry layers derived from RO data. Section 7 provides a summary and conclusions.

\section{Data and methods}

\subsection{The RO method}

The RO method (Melbourne et al., 1994; Hajj et al., 2002; Kuo et al., 2004) is a limb-sounding technique that provides near-vertical profiles of atmospheric refractivity $N$. The re- 
lation of $N$ to atmospheric temperature $T$, pressure $p$, and water vapor pressure $e$ can be approximated by the Smith and Weintraub (1953) formula:

$N=77.6 \frac{p}{T}+3.73 \times 10^{5} \frac{e}{T^{2}}+[\ldots]$.

Additional terms accounting for contributions from liquid water and the ionosphere can be neglected or are accounted for earlier in the retrieval. In the so-called dry air retrieval, the "dry temperature" is computed using Eq. (1) under the assumption $e=0$. For a detailed retrieval description, see Kursinski et al. (1997).

Water vapor pressure $e$ in Eq. (1) cannot be determined from an observed $N$ without ancillary temperature data from some other source (either observations, a model, or analysis). The two common techniques for this calculation are discussed in Appendix A, as well the influence of the ancillary data in the 1D-Var retrieval (Appendix B).

For this study, we downloaded data from $\mathrm{CDAAC}^{1}$ (COSMIC Data Analysis and Archive Center) for the RO missions COSMIC (Constellation Observing System for Meteorology, Ionosphere and Climate; reprocessed data cosmic2013), GRACE (Gravity Recovery and Climate Experiment; post-processed), Metop-A (Meteorological Operational Polar Satellite A; reprocessed data metopa2016), Metop-B (Meteorological Operational Polar Satellite B; post-processed), and TerraSAR-X (post-processed).

CDAAC provides profiles of physical parameters, which are derived by using a 1D-Var retrieval (COSMIC, 2005)). In the 1D-Var, ERA profiles (interpolated to the location and time of the RO measurement) are used as the initial (first-guess or a priori) temperature and moisture profiles in the iteration procedure. Furthermore, CDAAC also provides these a priori profiles, and collocated profiles from other (re)analyses. In this study we use these RO-collocated profiles from ERA and GFS for comparisons. ERA vertical profiles are provided at $25 \mathrm{hPa}$ steps between 1000 and $750 \mathrm{hPa}$ and at $50 \mathrm{hPa}$ steps between 750 and $300 \mathrm{hPa}$, yielding a total of 19 levels below $300 \mathrm{hPa}$. GFS analyses are given at $50 \mathrm{hPa}$ steps from 1000 to $300 \mathrm{hPa}$ and at 975 and $925 \mathrm{hPa}$ additionally, yielding a total of 16 levels below $300 \mathrm{hPa}$.

\subsection{The CONTRAST experiment}

The CONTRAST experiement was conducted over the western Pacific warm pool region during the season characterized by intense convective storms to study the impact of deep convection on chemical composition and ozone photochemical budget (Pan et al., 2017). The experiment was conducted from Guam $\left(13.5^{\circ} \mathrm{N}, 144.8^{\circ} \mathrm{E}\right)$ using the NSF/NCAR Gulfstream $\mathrm{V}(\mathrm{GV})$ research aircraft during January and February 2014. During the campaign, 16 research flights were conducted. Most research flights included several vertical pro-

\footnotetext{
${ }^{1}$ http://cdaac-www.cosmic.ucar.edu/cdaac/
}

files (covering altitudes from 0.1 to $15.2 \mathrm{~km}$ ), and together with take-offs and landings at Guam there were over 80 vertical profiles obtained during the experiment. We use the aircraft observations of temperature, pressure, and water vapor pressure to derive high-resolution vertical profiles of RH.

Water vapor was measured by the Vertical Cavity Surface Emitting Laser (VCSEL) hygrometer (absolute concentration of water vapor in molecules per cubic centimeter). It is designed to work throughout the troposphere (and also the lower stratosphere) and has an accuracy of $\pm 6 \%$ mixing ratio +0.3 ppmv and a precision of $\leq 3 \%$ (see Zondlo et al., 2010, for details). Temperature was measured by two Harco heated total air temperature sensors (estimated accuracy: $0.5^{\circ} \mathrm{C}$; precision: $<0.01^{\circ} \mathrm{C}$ ), pressure was measured using the Paroscientific, Ltd. sensor model 1000 transducer (accuracy: $0.1 \mathrm{hPa}$, precision: $<0.01 \mathrm{hPa})^{2}$. From the CONTRAST netcdf files, the variables used for $T, e$, and $p$ are ATX, EW_VXL, and PSXC.

\subsection{ERA-Interim reanalysis}

In addition to the RO-collocated ERA profiles (as described in Sect. 2.1), we downloaded ERA-Interim reanalysis fields from European Centre for Medium-Range Weather Forecasts (2009) for the time range of the CONTRAST experiment. They are available every $6 \mathrm{~h}$ at 00:00, 06:00, 12:00, and 18:00 UT. We use the data on the lowest 27 levels, from 1000 to $100 \mathrm{hPa}$. ERA uses a 4D-Var method and assimilates RS observations, AIRS radiances, and RO bending angles, among other in situ and satellite data (Dee et al., 2011).

\subsection{Radiosonde, AIRS, and MTSAT-2 observations}

RS data from Guam were downloaded from NOAA ${ }^{3}$. Data are available at approximately midnight and noon UT (10:00 and 22:00 local times, respectively). Measurements are taken at standard pressure levels and significant thermodynamic levels. To convert the pressure grid to altitude, we used a constant temperature gradient of $6.5 \mathrm{~K} \mathrm{~km}^{-1}$.

AIRS is a cross-track scanning instrument on the NASA Aqua satellite. Its sun-synchronous, near-polar orbit is designed to cross the Equator from south to north at 13:30 local time. The NASA Goddard Sciences Data and Information Center provides AIRS retrieved data products, such as profiles of physical parameters (temperature, humidity) and trace gas constituents, on a daily basis. We downloaded the version 6 level 2 standard retrieval data ${ }^{4}$.

MTSAT-2 is a geostationary satellite located over Australia, East Asia, and the western Pacific, operated by the

\footnotetext{
${ }^{2}$ https://www2.acom.ucar.edu/sites/default/files/seac4rs/ StateParameters.pdf

${ }^{3}$ https://www.ncdc.noaa.gov/data-access/weather-balloon/ integrated-global-radiosonde-archive

${ }^{4} \mathrm{ftp}$ ://airs12.gesdisc.eosdis.nasa.gov/ftp/data/s4pa/Aqua_AIRS_ Level2/AIRS2RET.006/
} 
Japan Meteorological Agency. Detailed information can be found at Knapp (2008). MTSAT-2 carries an imaging telescope, backed by detectors for five wavelength channels.

We use data from the infrared channel (10.3 to $11.3 \mu \mathrm{m})$ and the water vapor channel ( 6.5 to $7 \mu \mathrm{m})$. We downloaded MTSAT-2 data from NOAA ${ }^{5}$.

The sampling characteristics of the different observation and model data sets compared in this study vary greatly. The radiosonde and aircraft data are essentially point measurements. Radiosonde measurements are taken on standard pressure levels and significant thermodynamic levels, which results in the vertical resolution varying strongly within the profile (from less than 20 to almost $1000 \mathrm{~m}$ ). The vertical resolution of the aircraft measurements is around $10 \mathrm{~m}$. The horizontal footprint of the radio occultation profiles is $\sim 200 \mathrm{~km}$ while the vertical resolution is 100 to $300 \mathrm{~m}$ (Anthes, 2011). The AIRS level 2 products are reported on 28 standard pressure levels between 1100 and $0.1 \mathrm{hPa}$. They have a horizontal resolution of $50 \mathrm{~km}^{6}$ and a vertical resolution of $\sim 1 \mathrm{~km}$ for temperature and $\sim 2 \mathrm{~km}$ for humidity ${ }^{7}$. For the two models used in this study, we used GFS and ERA interpolated to the time and location of the RO profile. Furthermore, we used the ERA field, for which the horizontal footprint is given by the horizontal grid size $\left(0.7^{\circ} \times 0.7^{\circ}\right.$, about $78 \mathrm{~km} \times(68$ to $78) \mathrm{km}$, depending on the latitude). The vertical resolution is given by the model pressure levels every 25 or $50 \mathrm{hPa}$ (resulting in a vertical resolution between 200 to $1000 \mathrm{~m}$ ).

Because both radiosondes and the aircraft measurements are essentially rapid-response point values and have high vertical resolution, they are capable of measuring turbulence and small-scale horizontal features (such as individual clouds). AIRS, RO, and models, in contrast, represent averages over much larger horizontal and vertical scales of observation (larger horizontal and vertical footprints). Thus different volumes of air are sampled and compared, leading to representativeness errors or differences due to their different horizontal and vertical footprints, especially when measuring fields with high temporal and spatial variability such as water vapor and relative humidity.

In addition, all the observations and model data occur at different locations and times. The RS, RO, and aircraft observations occur at different horizontal positions in the vertical (can be $\sim 100$ to $200 \mathrm{~km}$ ) as the balloons, satellites, and aircraft move during the "vertical" sounding. All of these differences make comparisons challenging, adding to the uncertainties associated with each individual data set, and must be considered when interpreting the results.

\footnotetext{
${ }^{5}$ http://www.ncdc.noaa.gov/gibbs/availability/2014-02-20

${ }^{6}$ http://disc.gsfc.nasa.gov/uui/datasets/AIRS2RET_V006/ summary

${ }^{7}$ http://airs.jpl.nasa.gov/data/physical_retrievals
}

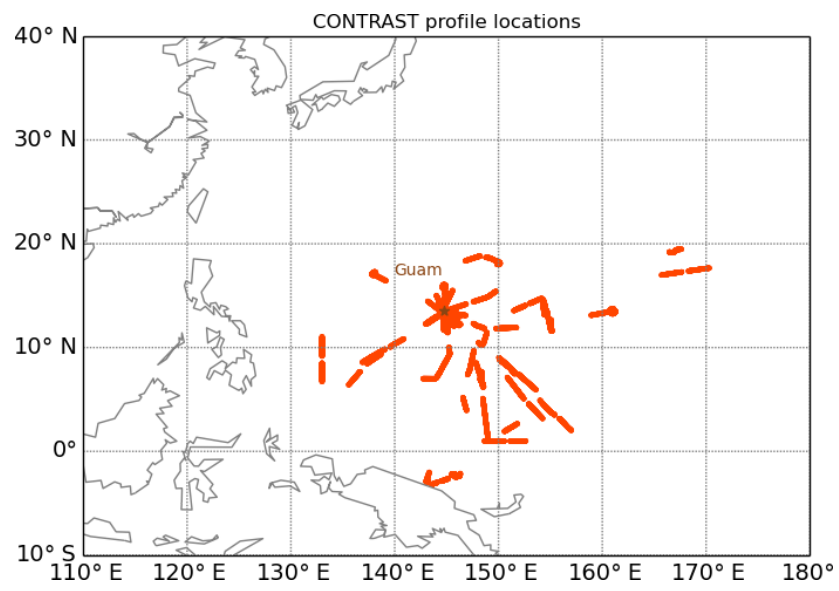

Figure 1. Profiles extracted from the CONTRAST flights during the experiment.

\subsection{Collocating CONTRAST and RO profiles}

From the 16 research flights, we extracted 75 profiles that extend over at least $6 \mathrm{~km}$ altitude and are within the region $5^{\circ} \mathrm{S}$ to $20^{\circ} \mathrm{N}$ latitude, 130 to $170^{\circ} \mathrm{E}$ longitude (Fig. 1). We tried different criteria for maximum time and distance for collocating RO with CONTRAST profiles. We made these comparisons only for the lowest $10 \mathrm{~km}$, since RO observations do not provide reliable moisture values at altitudes above about $8 \mathrm{~km}$ (Kishore et al., 2011). Aircraft-RO profile pairs with less than $4 \mathrm{~km}$ overlap in the vertical were discarded (CONTRAST profiles are mostly limited by their maximum altitude; RO profiles are limited by their minimum altitude). The time and space coincidence criteria tested included $3 \mathrm{~h}$ and $600 \mathrm{~km}, 12 \mathrm{~h}$ and $300 \mathrm{~km}$, and $24 \mathrm{~h}$ and $200 \mathrm{~km}$, yielding 37,41 , and 24 profile pairs, respectively. Note that the shortest time windows in these criteria correspond to the longest spatial intervals; this is done to ensure enough pairs in sets matching each of the criteria. Using a criterion of the shortest time and space separation would not yield enough pairs to make the results as meaningful. As shown in Sect. 5 below, all three of our criteria gave similar results; thus we only show results for the $3 \mathrm{~h}$ and $600 \mathrm{~km}$ criteria.

\section{Individual profile comparisons}

Figure 2 shows an example of a dry layer sampled by the CONTRAST research flight 2 profile d (rf02d) and the collocated RO profile (Metop-A) for the parameters RH, $T, q$, and $N$. RH (upper left) shows a typical dry layer structure. There is a strong drop in RH at the bottom of the layer (at $\sim 2.5 \mathrm{~km}$ ) from $>80$ to $<10 \%$. All profiles (CONTRAST, RO, ERA, and GFS) show extremely dry air above $4 \mathrm{~km}$. This layer is particularly thick and the $\mathrm{RH}$ remains below $20 \%$ up to $10 \mathrm{~km}$. The RO profile shows a remarkably similar shape when compared to CONTRAST, including the sharp humid- 

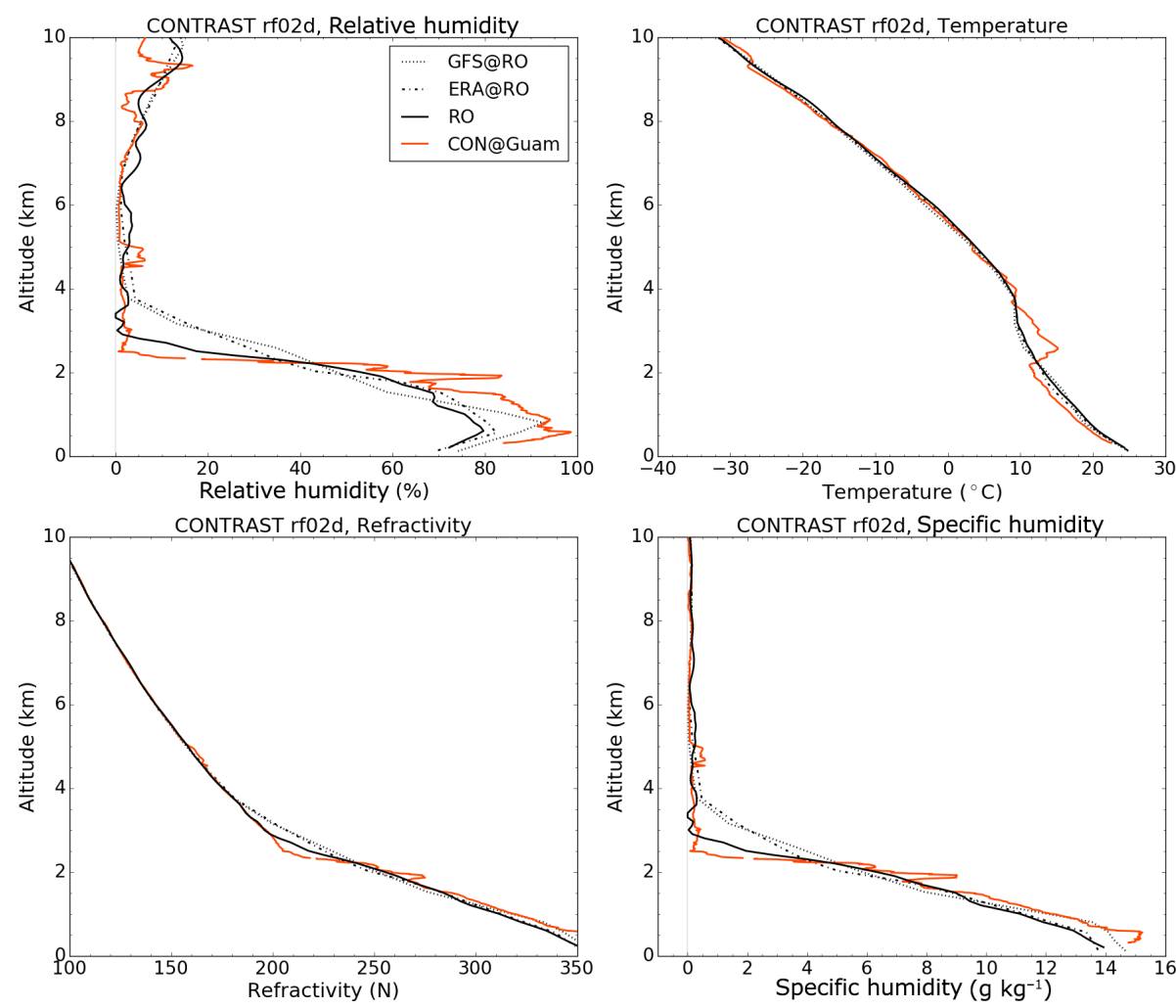

Figure 2. RH, $T, N$, and $q$ profiles for CONTRAST (solid orange), RO (solid black), and RO-collocated profiles (ERA: dashed-dotted black; GFS: dotted black). Profile times and locations: CONTRAST on 14 January 2014, 00:58-01:11 UT, at $19.2^{\circ} \mathrm{N}, 166.5^{\circ} \mathrm{E}$; RO on 13 January $2014,22: 18 \mathrm{UT}$, at $17.7^{\circ} \mathrm{N}, 164.4^{\circ} \mathrm{E}$. The profiles are about $3 \mathrm{~h}$ and $390 \mathrm{~km}$ apart.

ity gradient at the bottom of the dry layer. Both ERA and GFS show a less sharp vertical moisture gradient, partly due to lower vertical resolution (RO provides 80 levels between the surface and $8 \mathrm{~km}$, while ERA and GFS provide 18 and 15 levels, respectively). Profile differences are largest in the lowest $2.5 \mathrm{~km}$, where RO and ERA RH are up to $20 \%$ lower than the CONTRAST and GFS RH.

The aircraft $T$ profile (Fig. 2, upper right) shows a strong inversion at the altitude of the bottom of the dry layer, as has been described by, e.g., Mapes and Zuidema (1996). Neither ERA and GFS nor RO not detect this strong inversion. RO generally has the capability to resolve such strong inversions in the middle and upper troposphere (Anthes, 2011). We conclude that RO not showing the $T$ inversion could be explained by two factors: (1) CONTRAST and RO have different $N$ values at this altitude (see Fig. 2, lower left). This implies that there has to be a difference in $T$ and/or $e$ at this altitude, too. (2) The 1D-Var retrieval generally produces an RO $T$ close to the first-guess $T$, which does not show the inversion, and changes mainly $e$ in the adjustment of the firstguess $N$ towards the measured RO $N$.

Specific humidity $q$ (lower right) shows extremely dry conditions above $2.5 \mathrm{~km}$, but in less extreme cases dry layers are harder to detect using this parameter since it generally de- creases exponentially with altitude. Thus we mainly use RH to investigate dry layers.

Figure 3 shows two more examples for CONTRAST-RO pairs (Metop-B and COSMIC-FM6). In the left panel, CONTRAST depicts a dry layer from 2.5 to $5.5 \mathrm{~km}$, a relatively moist layer from 5.5 to $6.5 \mathrm{~km}$, and very dry air from 6.5 to $8 \mathrm{~km}$. The RO RH shows a very similar overall structure. Major differences are again in the lowest $2 \mathrm{~km}$, where CONTRAST, GFS, and ERA RH are up to $20 \%$ higher than RO $\mathrm{RH}$, and between 2.5 and $4 \mathrm{~km}$, where CONTRAST RH is up to $20 \%$ lower. Furthermore, both GFS and ERA miss the $1 \mathrm{~km}$ thick moist layer around $6 \mathrm{~km}$.

Figure 3, right, shows profiles with two drier layers in the mid-troposphere (at 3 and $5 \mathrm{~km}$ ), but no extreme dryness. Both ERA and GFS show the correct overall shape of the RH profile, but they are often 20 to $30 \%$ drier or moister than the CONTRAST RH. Again, RO captures more vertical structure than the models.

Generally both of these examples show how well the RO $\mathrm{RH}$ profile structure agrees with the one from CONTRAST. 

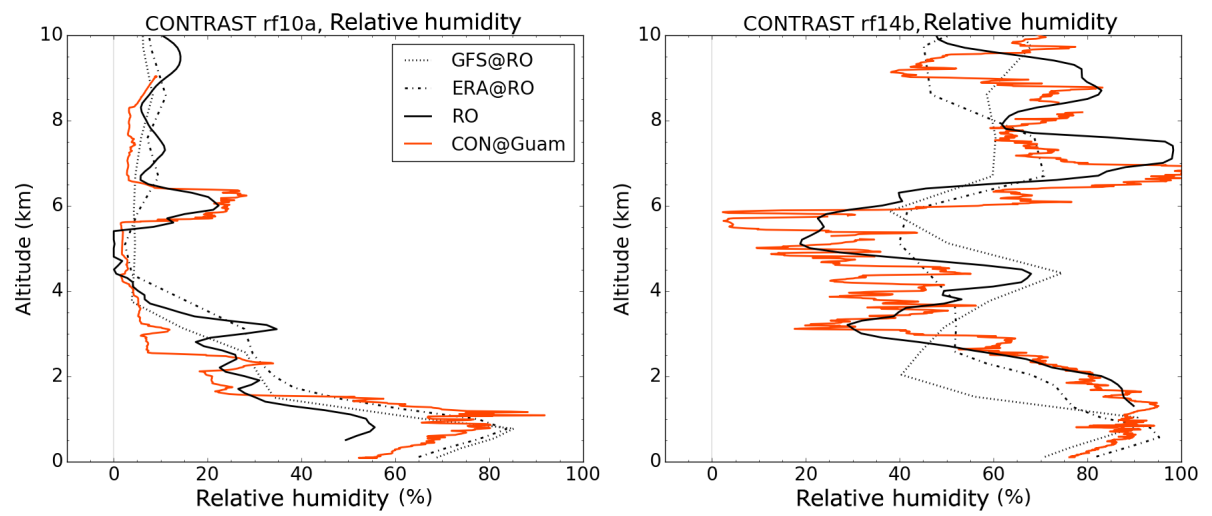

Figure 3. RH profile for CONTRAST (solid orange), RO (solid black), and RO-collocated profiles (ERA: dashed-dotted black; GFS: dotted black). Profile times and locations: CONTRAST (left) on 8 February 2014, 00:17-00:32 UT, at $13.5^{\circ} \mathrm{N}, 144.8^{\circ} \mathrm{E}$; RO (left) on 7 February 2014, 22:57 UT, at $13.9^{\circ} \mathrm{N}, 148.1^{\circ}$ E. CONTRAST (right) on 22 February 2014, 09:09-09:35 UT, at $13.5^{\circ} \mathrm{N}, 144.8^{\circ} \mathrm{E}$; RO (right) on 22 February $2014,12: 06 \mathrm{UT}$, at $15.6^{\circ} \mathrm{N}, 148.1^{\circ} \mathrm{E}$.

\section{Case study: research flight 13}

We found that many CONTRAST vs. RO profile pairs matched very closely, but some of the pairs showed RH differences of more than $60 \%$ at certain levels. In this section we look into one of these cases in more detail to help explain these strong discrepancies. We consider two specific profiles, one measured by CONTRAST starting at Guam on 19 February 2014, 17:00 UT (Fig. 4, top), and one landing at Guam a few hours later (20 February 2014, 00:22 UT; Fig. 4, bottom).

For both cases, the left side shows the profiles for CONTRAST, the closest collocated RO, the RO-collocated ERA and GFS profiles, a RS launched at Guam $\left(\mathrm{RS}_{\mathrm{G}}\right)$, and two AIRS profiles (one closest to Guam, labeled as AIRS $_{\mathrm{G}}$; and one closest to the RO profile, labeled as AIRS $_{R O}$ ). Table 1 lists the time differences and distances between these profiles.

The right plots show the ERA RH field at $500 \mathrm{hPa}$, closest in time to the respective CONTRAST profiles. Also shown are the ERA ozone values and winds. The location of Guam is marked by a white X. CONTRAST, RO, RS, and AIRS profiles are labeled. Additional squares indicate other RO measurements. The color filling of the RO symbols (white squares) varies with the RH of the RO observation at this level, with the same color code as the ERA RH analysis (color bar). It is noteworthy that in almost all the cases the colors (and hence $\mathrm{RH}$ ) of the RO observations agree very closely with the ERA values.

In Fig. 4, top left, all profiles show a deep dry layer. The depth of the layer varies slightly between the data sets. For CONTRAST, RS, and RO the depth with $\mathrm{RH} \leq 10 \%$ varies between 5 and $6.5 \mathrm{~km}$. Both the ERA and GFS profiles and both AIRS profiles show a less sharp transition from moist to dry. The models also show a generally thinner dry layer. Major differences between the data sets occur below $2 \mathrm{~km}$, where RO is significantly drier than all other data sets. The
GFS profile agrees with the drier RO profile down to about $1 \mathrm{~km}$ and then strongly increases in RH. Sometimes superrefraction can cause a dry bias in RO profiles in the lowest few kilometers, which is probably the case in this particular RO profile.

Figure 4, top right, shows the ERA RH field at $500 \mathrm{hPa}$ for the whole region. The large-scale region of very dry air extends from 110 to $180^{\circ} \mathrm{E}$ with a width of 1600 to $2200 \mathrm{~km}$. It also shows the high horizontal variability of moisture. In some areas, extremely strong horizontal RH gradients occur, which clearly mark the edge of the dry air mass. In these areas RH can increase from less than $20 \%$ to more than $70 \%$ within $100 \mathrm{~km}$. And since this is a model field, in which the gradients are likely to be smoother than the real atmosphere, the actual gradient could be even sharper. In this figure, it is also clearly visible that all the profiles from the left panel are located in the same air mass. Although ozone is not a focus of this study, we include contour lines of ozone in Fig. 4 (right panels) to illustrate that the ERA ozone fields show, in general, a coincidence of high ozone values with very dry air, suggesting the origin of at least some of the dry air from the lower stratosphere.

Next we consider the same region about $6 \mathrm{~h}$ later (Fig. 4, bottom panels). The profiles (left) show that the dry layer persists at Guam and is even deeper for CONTRAST. The RS profile and the AIRS profile at Guam still show a very deep dry layer. However, the RO shows only a very shallow dry layer, and RH increases from less than $20 \%$ to more than $80 \%$ between 3.5 and $4.5 \mathrm{~km}$. The RO-collocated ERA and GFS profiles lack the dry layer entirely, having their RH minima at 45 and $50 \%$, respectively. They also both increase above $3.5 \mathrm{~km}$ to around $80 \%$. The AIRS profile at the RO location starts much drier than RO, ERA, or GFS at the surface. Overall, the AIRS profile has the same shape as RO, ERA, and GFS. It has weaker dry-moist transitions, similar to the (re-)analyses, and it stays drier than the other data sets 

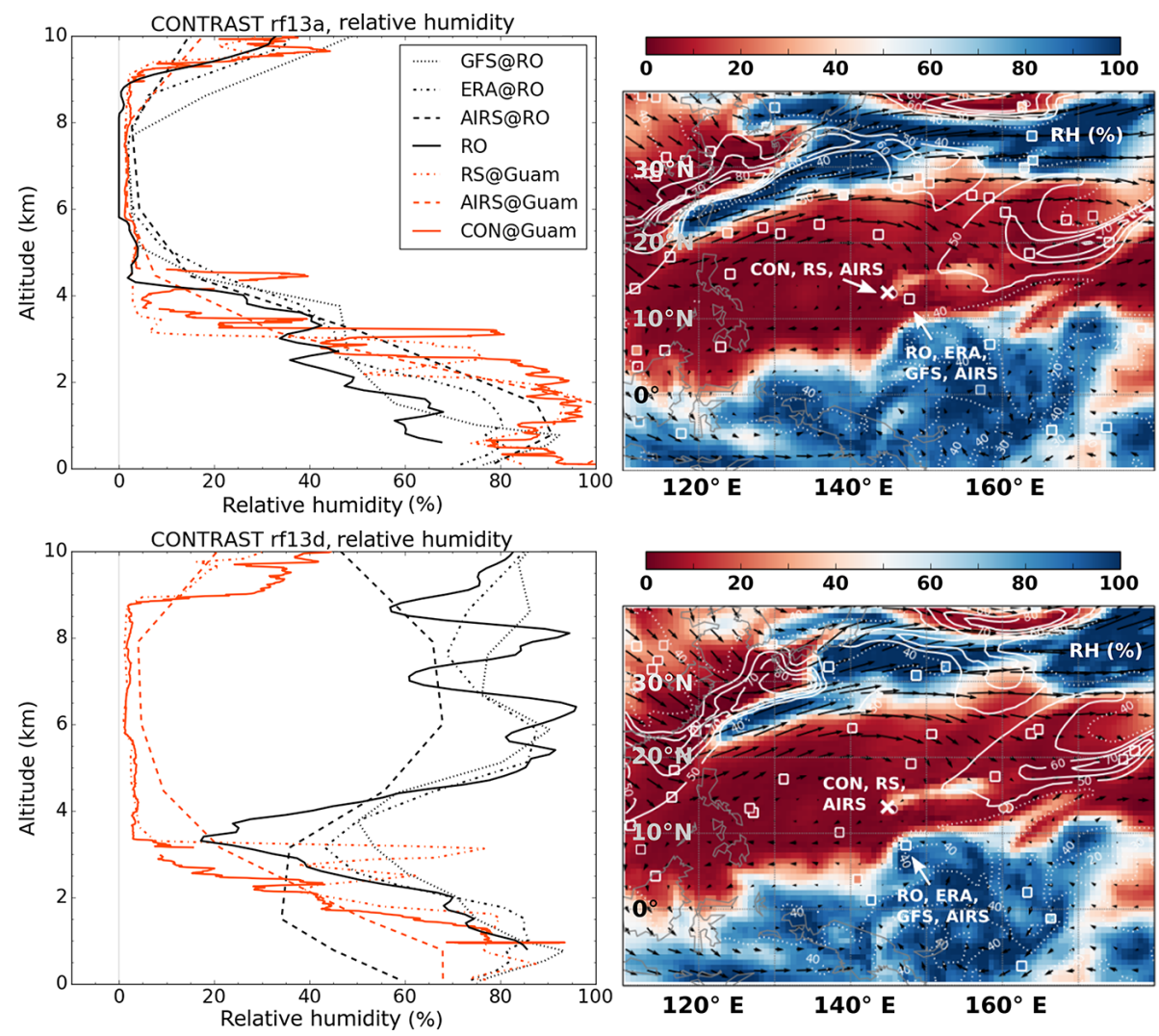

Figure 4. Two snapshots of the troposphere for (top) 19 February 2014 around 18:00 UT and (bottom) 20 February 2014 around 00:00 UT. Left panels: profiles for CONTRAST, RO, ERA, GFS, RS, and AIRS for the 2 days. Right panels: ERA RH (\%, color shading) at 500 hPa, ozone values (white contours: values $\geq 50 \mathrm{ppbv}$ are solid, otherwise dashed), and winds (black arrows). The white $\mathrm{X}$ marks the location of Guam. The locations of CONTRAST, RO, RS, and AIRS profiles are marked. Additional squares indicate other RO measurements. The squares marking the locations of the RO and CONTRAST locations are colored according to the RH of each profile at the $500 \mathrm{hPa}$ level (matching the color bar).

Table 1. Distances and time differences between different the collocated profiles of rf13a and rf13d at the lowest point for each profile. Note that both the aircraft and RS profile will move away from Guam with higher altitudes and that RO profiles are also not completely vertical, especially in the lower and mid-troposphere.

\begin{tabular}{|c|c|c|c|c|c|}
\hline Profile 13a & & & & & \\
\hline & $\mathrm{RO}-\mathrm{CON}$ & $\mathrm{RS}_{\mathrm{G}}-\mathrm{CON}$ & $\mathrm{AIRS}_{\mathrm{G}}-\mathrm{CON}$ & $\mathrm{AIRS}_{\mathrm{RO}}-\mathrm{CON}$ & $\mathrm{AIRS}_{\mathrm{RO}}-\mathrm{RO}$ \\
\hline Distance $(\mathrm{km})$ & 345 & 4 & 16 & 331 & 18 \\
\hline Time diff (min) & -117 & -289 & -70 & -70 & 47 \\
\hline \multicolumn{6}{|l|}{ Profile 13d } \\
\hline & $\mathrm{RO}-\mathrm{CON}$ & $\mathrm{RS}_{\mathrm{G}}-\mathrm{CON}$ & $\mathrm{AIRS}_{\mathrm{G}}-\mathrm{CON}$ & $\mathrm{AIRS}_{\mathrm{RO}}-\mathrm{CON}$ & $\mathrm{AIRS}_{\mathrm{RO}}-\mathrm{RO}$ \\
\hline Distance $(\mathrm{km})$ & 599 & 4 & 34 & 588 & 128 \\
\hline Time diff (min) & 87 & 1 & 236 & 234 & 147 \\
\hline
\end{tabular}

above $4 \mathrm{~km}$. Comparing the two AIRS profiles confirms the credibility of both RO and ERA: the strong difference between the aircraft profile and RO profile is neither an ERA nor an RO error, but caused by the combination of an imperfect collocation and strong spatial variability.
The lower right panel in Fig. 4 shows that the RO (and thus also the RO-collocated ERA and GFS) profiles are located in the moist air mass, just a few tens of kilometers from the edge of the moist-dry boundary, with much higher moisture 

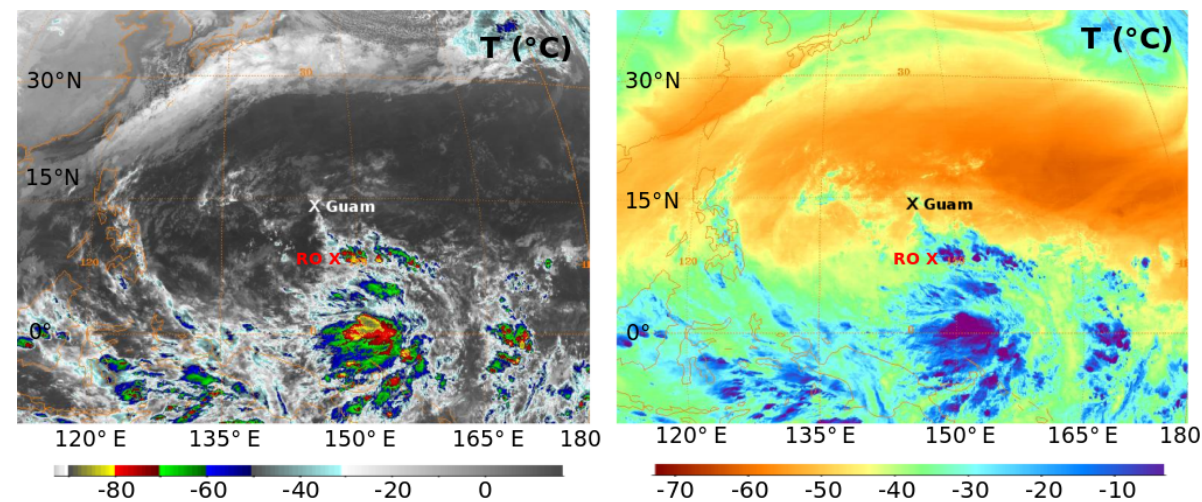

Figure 5. MTSAT-2 satellite images of brightness temperatures for 20 February 2014 around 00:00 UT. Left: MTSAT-2 IR (10.3 to $11.3 \mu$ m); right: MTSAT-2 IR water vapor $(6.5$ to $7 \mu \mathrm{m})$.

Table 2. Mean, RMS, and Pearson $R$ coefficients for differences in relative humidity of RO-CONTRAST, ERA-CONTRAST, and GFSCONTRAST for three different collocation criteria.

\begin{tabular}{llrrr}
\hline & & $3 \mathrm{~h} 600 \mathrm{~km}$ & $12 \mathrm{~h} 300 \mathrm{~km}$ & $24 \mathrm{~h} 200 \mathrm{~km}$ \\
644 points & 687 points & 419 points \\
\hline \multirow{2}{*}{ RO-CONTRAST } & mean & -4.0 & -6.5 & -0.2 \\
& RMS & 21.3 & 23.4 & 22.5 \\
& Pearson $R$ & 0.782 & 0.758 & 0.751 \\
\hline \multirow{2}{*}{ ERA-CONTRAST } & mean & -3.9 & -5.4 & 0.6 \\
& RMS & 20.0 & 20.5 & 21.8 \\
& Pearson $R$ & 0.807 & 0.807 & 0.760 \\
\hline \multirow{2}{*}{ GFS-CONTRAST } & mean & -5.0 & -6.3 & -0.1 \\
& RMS & 20.7 & 21.4 & 21.9 \\
& Pearson $R$ & 0.799 & 0.798 & 0.757 \\
\hline
\end{tabular}

values above $3 \mathrm{~km}$. This explains the very different profiles in the left panel.

Finally, Fig. 5 shows satellite images from MTSAT-2 for approximately the same time as the ERA field in Fig. 4, bottom right. The satellite images are cropped to the latitude and longitude range as ERA (as much as the different projections allowed). The Guam and RO locations are marked by an X.

The left panel depicts the brightness temperatures from IR in an atmospheric window (at 10.3 to $11.3 \mu \mathrm{m}$ ). It is derived from terrestrial IR radiation emitted by the Earth, cloud tops, and the atmosphere. Color enhancement shows the high, cold cloud tops south of Guam. Conditions are clear around Guam and the CONTRAST profile, but the RO profile is located in cloudy air.

The right panel shows the image from the MTSAT-2 water vapor channel. It depicts brightness temperatures derived from the water vapor emission spectrum between 6.5 and $7 \mu \mathrm{m}$. Higher amounts of water vapor absorb more radiation, which is re-emitted. Thus regions with high amount of water vapor, especially in the upper troposphere or above clouds, will have a higher brightness temperature. When compared to ERA (Fig. 4, bottom right), we see that the low RH re- gion has a much lower brightness temperature than the moist region south of Guam.

\section{Results of all collocations}

To get a general overview of profile pair differences we computed statistics (not shown) and created scatter plots for all collocated profiles. Since humidity has a strong spatial variation (as seen in Fig. 4, right) and also varies strongly with time, we tested different sets of collocation criteria (described in Sect. 2.5). CONTRAST profiles are smoothed by taking $60 \mathrm{~s}$ averages in each profile (resulting in about $300-500 \mathrm{~m}$ vertical resolution). The RO profiles are interpolated to the related CONTRAST altitude grid. We did comparisons for RO and CONTRAST, ERA and CONTRAST, and GFS and CONTRAST. Generally, all three sets of collocation criteria and all data set comparisons show similar results for both the profile statistics and scatter plots. To illustrate the similarities, we show the mean, root mean square (RMS), and Pearson $R$ correlation coefficient for RH for RO-CONTRAST, ERA-CONTRAST, and GFSCONTRAST differences for all three criteria in Table 2. We 

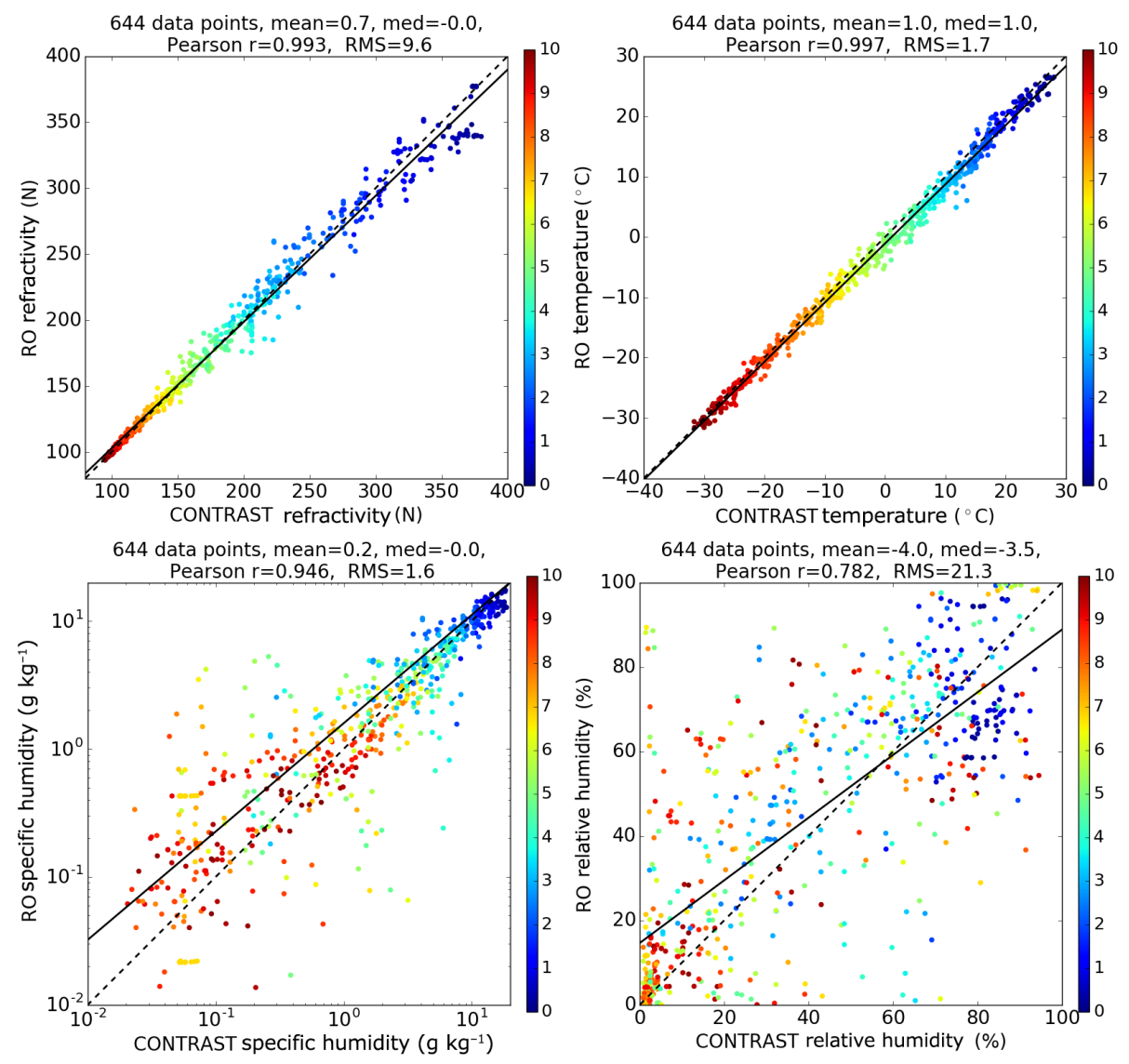

Figure 6. Scatter plots for $N$ (top left), $T$ (top right), $q$ (bottom left, logarithmic scale), and RH (bottom right) for all $3 \mathrm{~h} 600 \mathrm{~km}$ collocation pairs for RO and CONTRAST. The color indicates the altitude of the measurement.

chose RH due to our focus on tropospheric moisture in this paper. Furthermore, $\mathrm{RH}$ is the only parameter without some inherent vertical correlation due to a general decrease with altitude (i.e., $N, T$, and $q$ ).

Figure 6 shows the scatter plots for refractivity $N$, temperature $T$, specific humidity $q$, and $\mathrm{RH}$ for RO compared to CONTRAST. The color of the dot indicates the altitude from 0 to $10 \mathrm{~km}$ as shown in the color bar. The black solid line is the fitted linear regression, and the dashed black line indicates perfect agreement between the two data sets (slope $=1$, intercept $=0$ ).

The upper left panel depicts the $N$ comparison between RO and CONTRAST. $N$ decreases exponentially with altitude, so the spread is larger at lower altitudes (blue) than at higher altitudes (red). Overall, there is a high correlation between the two data sets, and the fitted regression (solid black line) agrees well with the line of perfect agreement (dashed black line).

$T$ (top right) also shows very good agreement (high correlation and little spread). We found a small warm bias of 0.5 to $1.5 \mathrm{~K}$ in CONTRAST temperatures when compared to any of the other data sets (RO, ERA, GFS). To test how much influence the collocation criteria have, we interpolated the
ERA field to the CONTRAST profile location (spatial difference for latitude and longitude $<0.5^{\circ}$; time difference less than $30 \mathrm{~min}$ ), which yielded a slightly smaller, more uniform bias. We conclude that there is likely a small $T$ bias in the aircraft temperatures, possibly because of the effects of solar radiation as most of the flights occurred during the daytime.

The specific humidity $q$ is depicted in the bottom left panel. The spread appears larger for low values (very dry air, $<1 \mathrm{~g} \mathrm{~kg}^{-1}$ ), but the scales in this panel are logarithmic, which makes small differences of dry values appear larger. RO $q$ values are biased positively compared to CONTRAST for low $q$ values and biased negatively for high $q$ values. Comparison on $q$ between CONTRAST and GFS in Randel et al. (2016) shows a similar bias. Because of the highly accurate aircraft water vapor and temperature measurements and the very small scale of the observation (essentially a point observation), the CONTRAST measurements are capable of detecting extremes of dry and moist air more frequently than RO observations or model estimates, whose data represent averages over larger scales.

RH plots (bottom right) are highly scattered and have a lower correlation coefficient of around 0.78 with a bias and large spread in the data sets. The moist bias of RO for very 

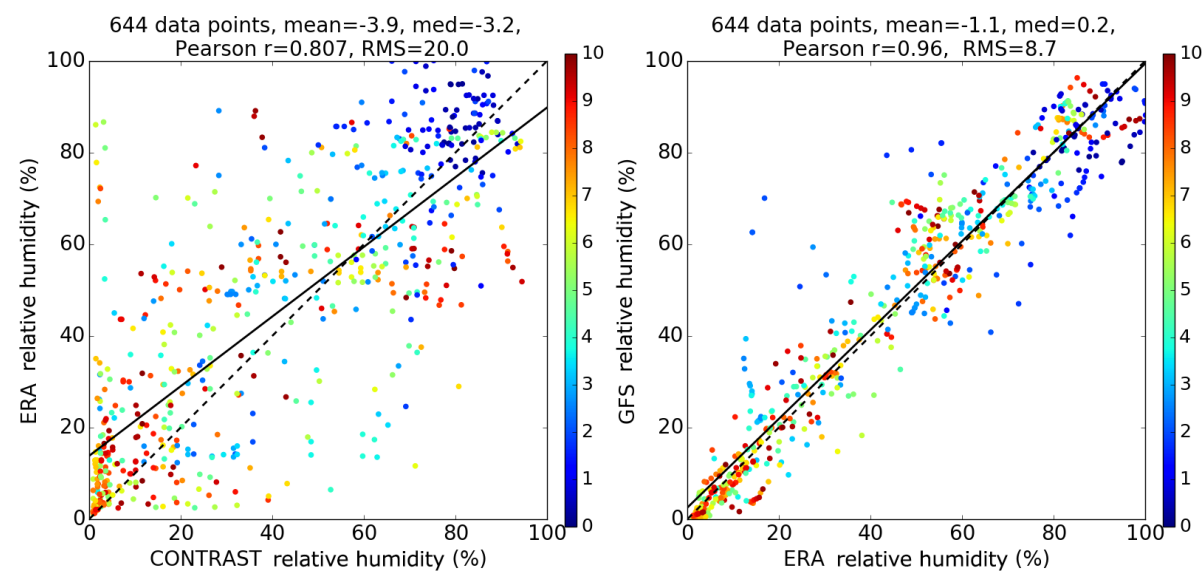

Figure 7. Scatter plots for RH for all $3 \mathrm{~h} 600 \mathrm{~km}$ collocation pairs for (left) ERA and CONTRAST on the $60 \mathrm{~s}$ smoothed CONTRAST altitude grid and (right) GFS and ERA on the ERA (pressure) grid. The color indicates the altitude of the measurement (left: km; right: hPa).

dry air was already noted in the paragraph above. Thus CONTRAST shows a much higher frequency of very low RH values than both RO (Fig. 6 lower right) and ERA (Fig. 7, left). The large spread can be explained by several factors: (1) RH is sensitive to both small variations in $T$ and $q$, and thus representativeness differences or errors of both $T$ and $q$ contribute to differences in RH; (2) RH does not have a vertical profile with a mean structural or climatological variation in the vertical as $N, T, q$ do (with an overall decrease with altitude); and (3) RH can undergo extremely strong changes in the vertical (80\% RH change over $1 \mathrm{~km}$ in Fig. 2), which leads to strong differences between two data sets if they do not capture this jump of RH at exactly the same altitude.

Furthermore, comparisons using 8 years of RS (two stations) and RO data using very tight collocation criteria ( $1 \mathrm{~h}$, $100 \mathrm{~km}$; figure not shown) also showed highly scattered data for RH, which indicates that collocation errors are not the dominant factor in the large scatter between RO and CONTRAST relative humidities.

Figure 7, left, compares ERA and CONTRAST RH, which shows a similar strong scatter as RO and CONTRAST. This suggests that the high variability in the CONTRAST data set also plays a role in the strong scatter of RH. Both the RO and ERA data sets are horizontally smoothed: RO shows an average over about $200 \mathrm{~km}$ (limb-sounding), and ERA is interpolated from the nearest grid points to the location of the profile (horizontal resolution is $<0.7^{\circ}$ in latitude and longitude). Finally, Fig. 7, right, compares GFS to ERA (this comparison is done on the ERA pressure grid). The correlation between the two analyses is high, but the scatter is surprisingly large considering these are smooth model data sets. This shows how highly variable $\mathrm{RH}$ is.

\section{Global distribution}

Having shown that the RO observations are capable of detecting extremely dry layers in the tropical western Pacific region, we carried out a global climatology of dry layers using only RO data. AIRS data have been used before to find tropical dry regions within areas of convection (OLR $<240 \mathrm{~W} \mathrm{~m}^{-2}$; Casey et al., 2009); however, AIRS cannot provide reliable measurements below clouds.

Figure 8 shows the global occurrence (percentage of observations) for $\mathrm{RH}<10 \%$ on the $320 \mathrm{~K}$ potential temperature level for December-January-February (DJF) and JuneJuly-August (JJA) 2014. We use the $320 \mathrm{~K}$ level because dry air travels from the stratosphere into the troposphere along isentropes. The $320 \mathrm{~K}$ level is at about $600 \mathrm{hPa}$ or $4.5 \mathrm{~km}$ in the tropics and slopes to higher altitudes $(\sim 9 \mathrm{~km})$ in the extratropics. So the $320 \mathrm{~K}$ level represents the mid-troposphere in the tropics and the lower stratosphere in the extratropics.

Figure 8, left, shows the months DJF. Between 5 and $25^{\circ} \mathrm{N}$, almost the entire latitude band shows an occurrence of dry air for $50 \%$ of the time or more. The only break in the band is off the west coast of North and Central America. In some regions, dry layer occurrence is as high as $75 \%$, e.g., in parts of the Atlantic or near India and the Arab peninsula. Guam is located just on the edge of the band of high frequency of dry layer occurrence. In the SH, two regions with very strong occurrence are easy to identify: one off the west coast of South America, and one in the southern Atlantic Ocean.

In JJA (Fig. 8, right), dry layers occur over smaller regions of the world, but with a much higher frequency. In the SH, the entire region from mid-Atlantic via Africa and the Indian Ocean to Australia shows a frequency of occurrence of 80 to $100 \%$ of the time. In the NH, only a region in the northern east Pacific and the northeast Africa/eastern Mediterranean region show moderate to high occurrence. 

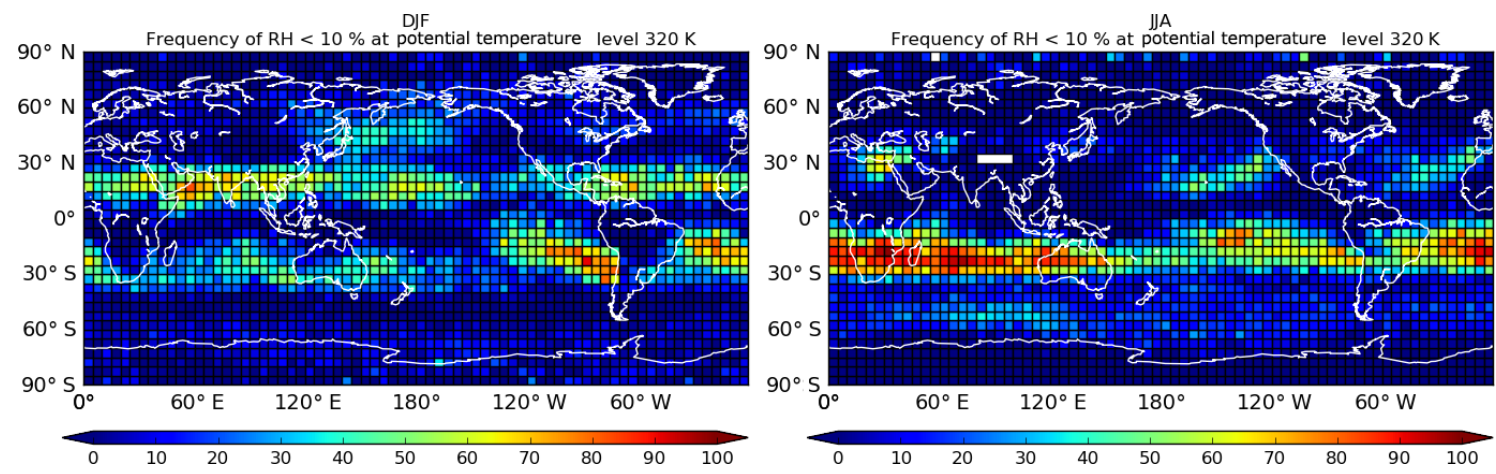

Figure 8. Frequency for RH $<10 \%$ at the potential temperature level $320 \mathrm{~K}$ for DJF and JJA 2014.

Overall, dry layers occur throughout the year in some regions of the $\mathrm{SH}$, but there is also a seasonal cycle with higher occurrence in the winter hemisphere. This behavior is consistent with the dry layer climatology derived from ERA (results not shown) and from GFS data in Randel et al. (2016).

\section{Conclusions}

In this study we compared GPS RO profiles with multiple data sets to examine their ability to detect extremely dry layers in the lower and mid-troposphere in the tropics and subtropics. The comparisons were made in the tropical western Pacific, making use of the field experiment in that region during January and February 2014. We used data from the NSF/NCAR GV research aircraft as a reference for RO profiles. This is a challenging comparison, since the aircraft provides high-resolution profiles consisting of point measurements (capturing a lot of variability), whereas the RO technique is a limb-sounding technique (measuring the limbintegrated value at each profile level). Furthermore, we used RS and AIRS profiles, as well as data from the GFS model and ERA reanalysis. Our main findings and conclusions are as follows:

1. Radio occultation is capable of detecting layers with very low humidity in the lower and mid-troposphere, despite the fact that the water vapor pressure is only a small fraction of the measured refractivity in dry air. Comparing RO to other types of observations also shows that the structure and intensity of dry layers are captured quite accurately.

2. Both simple and 1D-Var RO water vapor retrievals yield similar results, demonstrating the ability of RO to retrieve water vapor profiles with fine-scale vertical structure similar to that of the aircraft profile (Appendix A).

3. There is significant information content in the RO water vapor retrievals, and the 1D-Var retrieval does not depend strongly on an accurate first-guess (a priori) information (such as from ERA). However, poor a priori information for water vapor may have an effect of several Kelvin on the retrieved temperature (Appendix B).

4. When compared to CONTRAST, RO has a moist bias for low humidity values and a dry bias for high humidity values. Similar results are found when comparing $\mathrm{RO}$ to long records of tropical RS measurements (Appendix A).

5. Both the GFS and ERA analyses show the overall correct structure when compared with CONTRAST aircraft observations and RO. They often exhibit less small-scale vertical variations or sharp vertical gradients, probably due to lower vertical resolution.

6. A detailed case study illustrated how strong horizontal moisture gradients (more than 50\% RH change within $100 \mathrm{~km}$ ) can yield nearby profile pairs that strongly disagree, even though they are close in space and time.

7. Globally, dry layers occur throughout the year, mainly between 10 and $30^{\circ} \mathrm{N}$ and $\mathrm{S}$. Occurrence frequency is stronger in the winter hemisphere. The independent RO data confirm results from both ERA and GFS, which show a very similar seasonal occurrence of dry layers.

In summary, these diverse data sets show generally good agreement in spite of their large differences in sampling characteristics and technologies.

\section{Data availability}

For this study, we downloaded data from CDAAC (http:// cdaac-www.cosmic.ucar.edu/cdaac/; COSMIC Data Analysis and Archive Center) for the RO missions COSMIC (Constellation Observing System for Meteorology, Ionosphere and Climate; reprocessed data cosmic2013), GRACE (Gravity Recovery and Climate Experiment; post-processed), Metop-A (Meteorological Operational Polar Satellite A; reprocessed data metopa2016), Metop-B (Meteorological Operational Polar Satellite B; post-processed), and TerraSAR-X (post-processed). 
The CONTRAST data are available at https: //data.eol.ucar.edu/dataset/383.012. The ERA data are available at the NCAR Research Data Archive: http://rda. ucar.edu/datasets/ds627.0/. The radiosonde data are available at https://www.ncdc.noaa.gov/data-access/weather-balloon/ integrated-global-radiosonde-archive. The AIRS data have been downloaded from ftp://airsl2.gesdisc.eosdis.nasa. gov/ftp/data/s4pa/Aqua_AIRS_Level2/AIRS2RET.006/.

MTSAT-2 data have been downloaded from http: //www.ncdc.noaa.gov/gibbs/availability/2014-02-20. 


\section{Appendix A: RO water vapor retrievals}

The two common techniques to retrieve physical temperature and water vapor profiles from $\mathrm{RO}$ are the so-called simple retrieval (Kursinski and Hajj, 2001) and the 1D-Var retrieval. For the simple retrieval, $e$ is derived via Eq. (1) using the RO observed $N$, and $T$ and $p$ from an independent source (e.g., radiosonde, model, or analysis). Advantages of the simple retrieval are its simplicity and ease of calculation, and its independence of model moisture (and thus independence from errors in model moisture). Vergados et al. (2015) used the simple method for this reason, using ECMWF temperatures for the independent temperatures. Ware et al. (1996) (Eqs. 3 and 4) noted that for a perfect $N$ and $p$, the error (difference) in $e$ related to an error (difference) in $T$ can be approximated by

$$
\Delta e=\frac{2 T N-77.6 p}{3.73 \times 10^{5}} \times \Delta T .
$$

The simple method provides good results $(\Delta e<$ $0.25 \mathrm{hPa}$ ) in the lower troposphere if the ancillary temperature data are reasonably accurate $(\Delta T<1 \mathrm{~K})$. In the 1DVar procedure, a priori (first-guess or background) profiles of $T$ and $e$ are obtained from independent observations and adjusted toward the RO measurements by a statistical optimization procedure (Poli et al., 2002; COSMIC, 2005). The 1D-Var procedure considers the statistics of errors in the RO observations as well as the statistical errors in the a priori information, to achieve a consistent temperature and water vapor profile that minimizes, in a statistical sense, the errors in $T$ and $e$.

Because both the 1D-Var and simple method are used in different studies to estimate water vapor, it is important to understand how the results from the two methods compare. In this Appendix we compare the two methods using the data in our study by first showing an example and then statistics using a large number of data pairs. Figure A1 shows the parameters RH, $T, q$, and $e$ for the first-guess (ERA, solid) and retrieved from RO with the 1D-Var (dashed) and the simple retrieval (dotted) for an example profile.

The RH (top left) is very low between 4 and $9 \mathrm{~km}$. The simple retrieval and the 1D-Var agree very well up to $4 \mathrm{~km}$. At 4.2 and 6 to $9 \mathrm{~km}$, the simple retrieval produces a negative RH (due to negative $e$ values). In the simple retrieval, any error in $T$ will produce an error in $e$, and for dry air ( $e$ close to zero) this error may lead to an unphysical negative value for $e, q$, and $\mathrm{RH}$. The $1 \mathrm{D}$-Var can theoretically also produce negative values in these situations, but it is artificially set to a very small positive value $\left(10^{-6} \mathrm{hPa}\right)$ in the COSMIC CDAAC 1D-Var retrieval.

The RO 1D-Var and first-guess (ERA) $T$ (top right) agree very well; temperature differences are within $1.5 \mathrm{~K}$ throughout the profile. (The RO $T$ in the simple retrieval assumes
ERA $T$ to be the truth, so it is identical to the ERA $T$ in this figure.)

The bottom panels show $q$ and $e$. Both parameters become negative above $4.2 \mathrm{~km}$ in the simple retrieval.

Generally, the moisture profiles derived from both the simple retrieval and the 1D-Var show much more vertical structure than the ERA profile; this structure comes from the vertical structure of the RO refractivity profile. The above example shows that the simple and 1D-Var methods give very similar results for temperature, specific humidity, water vapor pressure, and even relative humidity up to the bottom of the very dry layer (a little above $4 \mathrm{~km}$ ) where the water vapor pressure becomes less than $0.1 \mathrm{hPa}$. The close agreement in this example is typical, as shown by a comparison of the simple and 1D-Var method over a large number of cases.

We compared values of $T, q$, and $\mathrm{RH}$ computed from the two methods, using ERA $T$ directly for the simple retrieval and ERA $T$ and $q$ as the first guess for the 1D-Var estimates, against RS data from Vacoas, Mauritus $\left(20.3^{\circ} \mathrm{S}, 57.5^{\circ} \mathrm{E}\right)$, which is located in a region that frequently contains very dry layers. We used the period 2006 to 2014, using collocation criteria of $2 \mathrm{~h}$ and $200 \mathrm{~km}$. Because of large uncertainties in radiosonde humidity measurements above $10 \mathrm{~km}$ (Miloshevich et al., 2006), we focus on comparisons over 1000 to $200 \mathrm{hPa}$.

Scatter plots of $q$ from the 1D-Var retrieval (left) and the simple retrieval (right) versus the independent radiosonde observations are shown in Fig. A2. The results are very similar with a correlation of 0.914 for the 1D-Var retrieval and 0.908 for the simple method.

Figure A3 uses the same data as above but shows the scatter plot of specific humidities from the 1D-Var versus simple retrieval. The retrieved values from the two methods are very similar with a correlation of 0.994 . Approximately 15 points (blue, i.e., pressure altitudes of about $800 \mathrm{hPa}$ ) show 1D-Var values that are significantly higher than the simple values. We suspected that these points were from profiles where superrefraction occurs. In the case of super-refraction, $N$ is biased negatively (Sokolovskiy, 2003) and $e$ from the simple retrieval, which uses an accurate estimate of $T$, will be too low. In 1D-Var, the negative RO $N$ bias will be mitigated to some extent and the resultant 1D-Var temperature will be too high and the water vapor pressure too low, but not as low as in the simple retrieval. Thus $e$ from the simple method will be significantly lower than the $e$ from the 1D-Var method under conditions of super-refraction.

To test this hypothesis, we checked all radiosonde profiles in the pairs for the criterion for super-refraction $(\mathrm{d} N / \mathrm{d} z<$ $-157 \mathrm{~N} \mathrm{~km}^{-1}$ ). If a profile contained this critical value at some pressure level, we marked all data points of that profile with an $\mathrm{X}$ in Fig. A3. Indeed, most of the points with strong differences between 1D-Var and simple appear to occur with super-refraction.

We note that neither the 1D-Var nor the simple method for computing water vapor pressure at high altitudes 

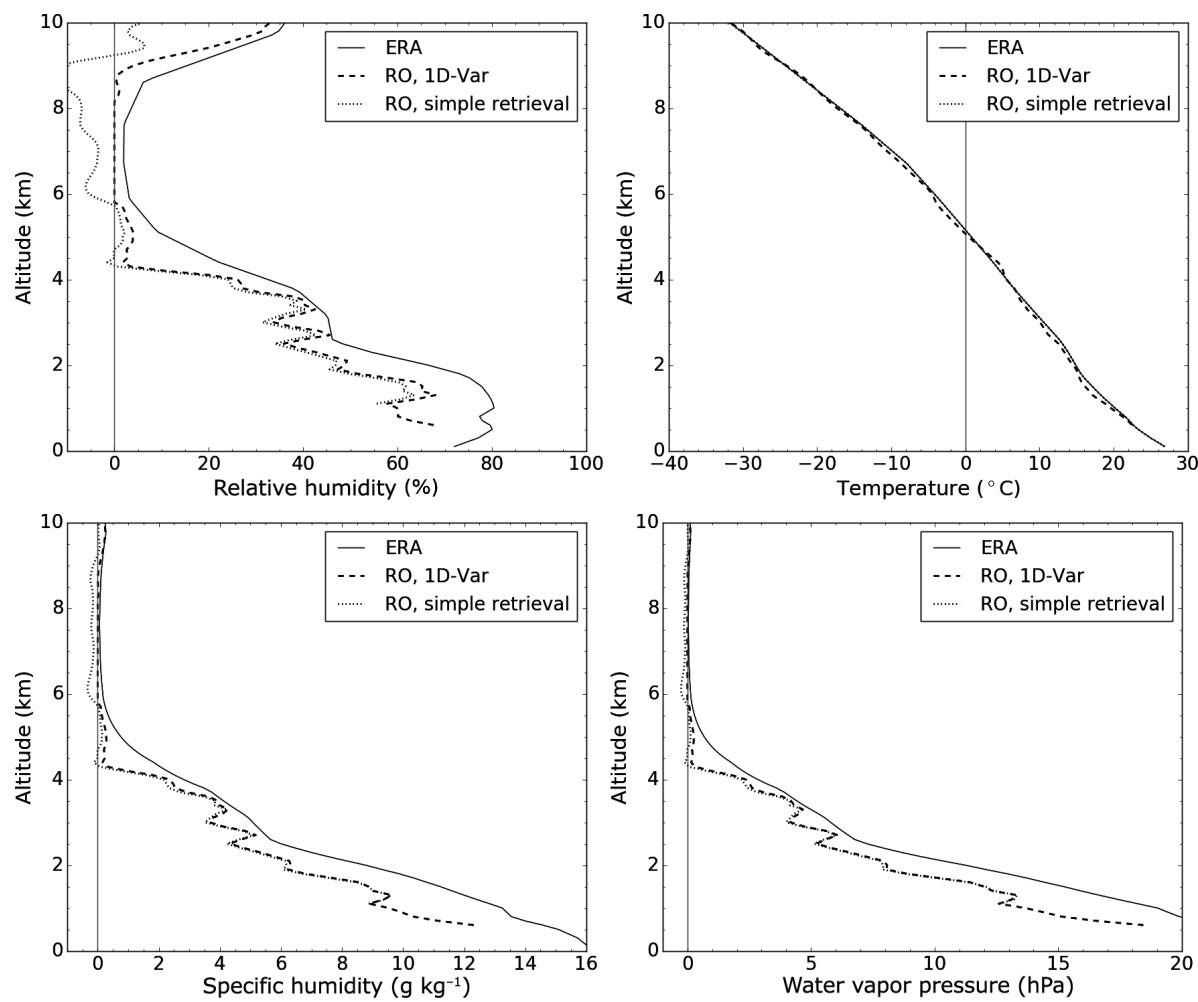

Figure A1. $T$, RH, $q$, and $e$ profiles for ERA (solid, a priori), RO 1D-Var (dashed), and RO simple retrieval (dotted).
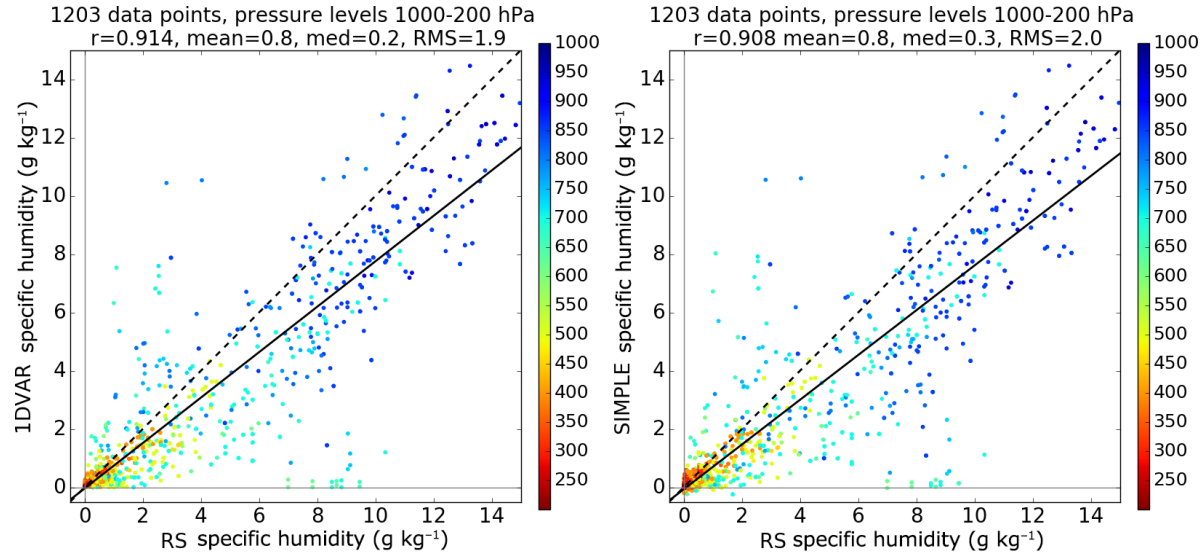

Figure A2. Specific humidity from the RO 1D-Var retrieval (left) and simple retrieval (right) versus radiosonde data. Collocation criteria: $2 \mathrm{~h}$ $200 \mathrm{~km}$, altitude range 1000 to $200 \mathrm{hPa}$.

$(p<200 \mathrm{hPa}$ ) from observed $\mathrm{RO}$ refractivity $N$ will provide reliable estimates, because at these altitudes water vapor contributes very little to the refractivity; i.e., the so-called "wet" term in Eq. (1) is less than $1 \%$ of the first, or "dry" term as noted by Wang et al. (2013). There is simply not enough information on water vapor pressure in refractivity at these altitudes to retrieve accurate estimates of water vapor. For example, the mean hurricane-season tropical atmosphere (Dunion and Marron, 2008) gives the following value of $T$ at $200 \mathrm{hPa}$ (about $12.4 \mathrm{~km}$ altitude): $T=-54.6^{\circ} \mathrm{C}(218.6 \mathrm{~K})$. The sat- uration vapor pressure at this temperature is $0.04 \mathrm{hPa}$; thus for $100 \%$ relative humidity, the dry term for $N$ is 71.0 and the wet term is 0.31 , or $0.4 \%$ of the refractivity value. For the above values, the relationship between errors in $e$ and $T$ (Eq. A1) gives $\Delta e=0.042 \Delta T(\mathrm{hPa})$. So a temperature error (difference) of $0.5 \mathrm{~K}$ gives a difference in $e$ of $0.021 \mathrm{hPa}$, which is more than $50 \%$ of the saturation vapor pressure at this temperature. This example illustrates the difficulty in calculating water vapor pressure and relative humidity in the upper troposphere. Vergados et al. (2014) estimated the re- 


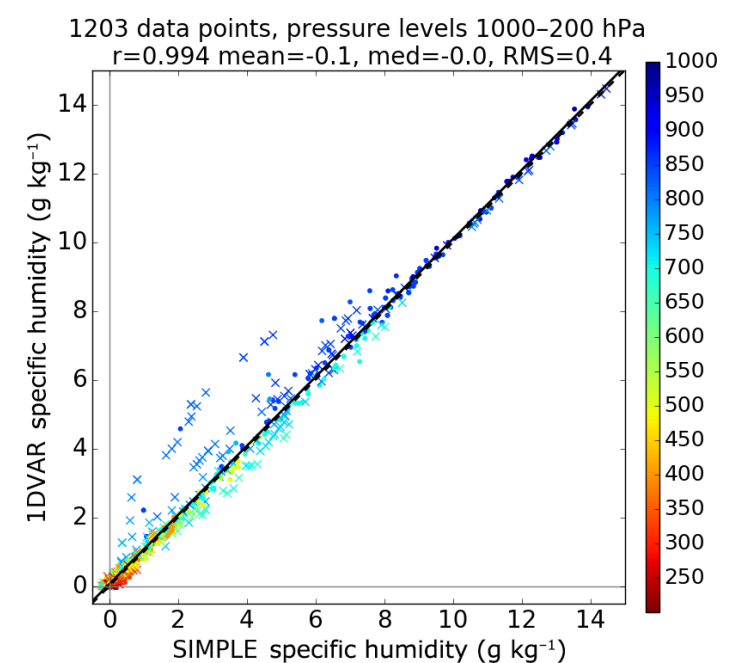

Figure A3. Specific humidity from the RO 1D-Var retrieval compared to the RO simple retrieval, using the same profiles as in Fig. A2. Points from profiles for which the collocated radiosonde profile experiences super-refraction are marked by an X.

trieval errors in specific humidity at different pressure levels $(925,850,700,500$, and $400 \mathrm{hPa})$. They estimated that in the lower troposphere $(925,850$, and $700 \mathrm{hPa})$ the percentage error in specific humidity for a temperature uncertainty of $1 \mathrm{~K}$ was less than $3 \%$ in the tropics, $6 \%$ in middle latitudes, and $10 \%$ in high latitudes. At $400 \mathrm{hPa}$, the percent errors grew to $18 \%$ in the tropics, $45 \%$ in middle latitudes, and $67 \%$ in high latitudes.

\section{Appendix B: Contribution of RO in the 1D-Var}

The simple retrieval of water vapor from $N_{\mathrm{RO}}$ and $T_{\text {model }}$ is strongly dependent on an accurate $T_{\text {model }}$ but completely independent from the a priori model water vapor. The 1D-Var, however, uses the a priori moisture from ERA. In this section we investigate how the $1 \mathrm{D}$-Var retrieval reacts to a poor humidity first guess and how much information the RO refractivity contributes in the 1D-Var.

As an experiment to test the sensitivity of the 1D-Var method to the first-guess water vapor profile, we change $e$ of the first guess such that the RH is greater than 20, 40, or $60 \%$ within the lowest $10 \mathrm{~km}$ (leaving $T$ unchanged). Then we use these fictitious a priori "high moisture" data in the 1D-Var retrieval. Figure B1 shows the results for the original $\mathrm{RO}$ and first guess and for the "high moisture" cases.
The top left panel shows RH: the three changed a priori profiles are clearly different from the original profile. At $4 \mathrm{~km}$, the original profile shows a RH of $<5 \%$, while the changed ones are 20 (dark red), 40 (red), and $60 \%$ (orange). Using these a priori in the 1D-Var yields the original (solid blue) RO and the "high moisture" ROs (solid, shades of red). The solid red lines all decrease strongly between 2.5 and $3 \mathrm{~km}$ and follow the shape of the original RO at all levels. Up to $5.5 \mathrm{~km}$, the difference is between 2 and $6 \%$. Above that, the RH profiles begin to fan out and differences up to $20 \%$ occur between 5.5 and $8 \mathrm{~km}$. Overall, the results show that $\mathrm{RO}$ refractivity contributes significant information to the water vapor in the 1D-Var retrieval and strongly corrects for the artificially high moisture from the a priori profiles.

The top right panel in Fig. B1 shows that the RO $T$ profiles show some differences due to the erroneous a priori water vapor profiles at all levels. Differences are $<1 \mathrm{~K}$ for the original and the $20 \%$ a priori case and $\sim 3 \mathrm{~K}$ for the original and the $60 \%$ a priori case.

The lower panels of Fig. B1 depict $q$ and $e$. They show how much the 1D-Var adjusts the high humidity values from the first guess towards the low, realistic humidity values. 

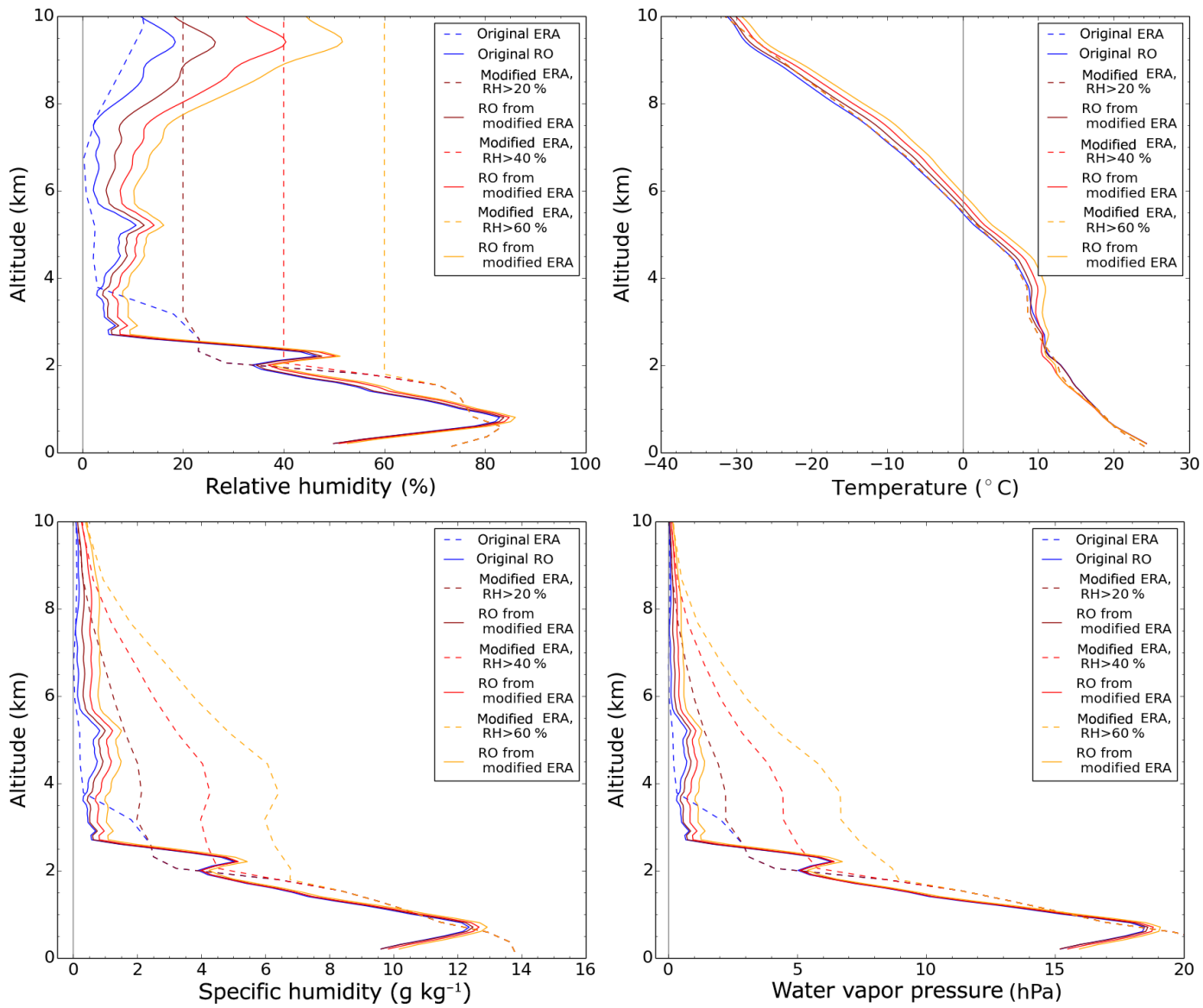

Figure B1. RH, $T, q$, and $e$ profiles with the original ERA first guess (dashed blue), the original 1D-Var output (solid blue), the "high moisture" first guess (dashed, shades of red), and the 1D-Var output for the modified first guess (solid, shades of red). 
Author contributions. Therese Rieckh and William Randel formulated the initial idea of this work. Richard Anthes and Shu-Peng Ho helped to develop the design of the study further. Together with U1rich Foelsche, they contributed ideas and provided valuable feedback. Therese Rieckh collected the data, performed all the computational work and coding necessary, performed the analysis, and prepared the manuscript. Richard Anthes and William Randel contributed significantly to the data analysis and the writing.

Competing interests. The authors declare that they have no conflict of interest.

Acknowledgements. Therese Rieckh, Richard Anthes, and ShuPeng Ho were supported by the NSF-NASA grant AGS-1522830. William Randel was supported through the NSF-UCAR cooperative agreement for the management of NCAR and NASA RNSS Science Team grant NNX12AQ18G.

The CONTRAST data set was provided by NCAR/EOL under sponsorship of the NSF (http://data.eol.ucar.edu/). The ERA data were provided by the Data Support Section of the Computational and Information Systems Laboratory, NCAR, which is sponsored by the NSF. We thank the COSMIC CDAAC team for providing the RO Level-2 data. We also thank Eric DeWeaver (NSF) and Jack Kaye (NASA) for their long-term advice and support to the COSMIC science program. COSMIC is supported by the National Space Office (NSPO) of Taiwan, NSF, NASA, NOAA, and the US Air Force.

We thank the two anonymous reviewers for their constructive comments and improving this manuscript.

Edited by: T. Islam

Reviewed by: two anonymous referees

\section{References}

Anthes, R. A.: Exploring Earth's atmosphere with radio occultation: contributions to weather, climate and space weather, Atmos. Meas. Tech., 4, 1077-1103, doi:10.5194/amt-4-1077-2011, 2011.

Berrisford, P., Kållberg, P., Kobayashi, S., Dee, D., Uppala, S., Simmons, A., Poli, P., and Sato, H.: Atmospheric conservation properties in ERA-Interim, Q. J. Roy. Meteorol. Soc., 137, 13811399, doi:10.1002/qj.864, 2011.

Brown, R. G. and Zhang, C.: Variability of midtropospheric moisture and its effect on cloud-top height distribution during TOGA COARE, J. Atmos. Sci., 54, 2760-2774, doi:10.1175/15200469(1997)054<2760:VOMMAI>2.0.CO;2, 1997.

Casey, S. P. F., Dessler, A. E., and Schumacher, C.: Five-Year Climatology of Midtroposphere Dry Air Layers in Warm Tropical Ocean Regions as Viewed by AIRS/Aqua, J. Appl. Meteorol. Clim., 48, 1831-1842, doi:10.1175/2009JAMC2099.1, 2009.

Cau, P., Methven, J., and Hoskins, B.: Representation of dry tropical layers and their origins in ERA-40 data, J. Geophys. Res., 110, D06110, doi:10.1029/2004JD004928, 2005.
Cau, P., Methven, J., and Hoskins, B.: Origins of Dry Air in the Tropics and Subtropics, J. Climate, 20, 2745-2759, doi:10.1175/JCLI4176.1, 2007.

COSMIC: Variational Atmospheric Retrieval Scheme (VARS) for GPS Radio Occultation Data, COSMIC technical report, version 1.1, University Corporation for Atmospheric Research, 2005.

Dee, D. P., Uppala, S. M., Simmons, A. J., Berrisford, P., Poli, P., Kobayashi, S., Andrae, U., Balmaseda, M. A., Balsamo, G., Bauer, P., Bechtold, P., Beljaars, A. C. M., van de Berg, L., Bidlot, J., Bormann, N., Delsol, C., Dragani, R., Fuentes, M., Geer, A. J., Haimberger, L., Healy, S. B., Hersbach, H., Hólm, E. V., Isaksen, L., Kållberg, P., Köhler, M., Matricardi, M., McNally, A. P., Monge-Sanz, B. M., Morcrette, J.-J., Park, B.-K., Peubey, C., de Rosnay, P., Tavolato, C., Tépaut, J.-N., and Vitart, F.: The ERA-Interim reanalysis: configuration and performance of the data assimilation system, Q. J. Roy. Meteorol. Soc., 137, 553597, doi:10.1002/qj.828, 2011.

Dunion, J. P. and Marron, C. S.: A Reexamination of the Jordan Mean Tropical Sounding Based on Awareness of the Saharan Air Layer: Results from 2002, J. Climate, 21, 5242-5253, doi:10.1175/2008JCLI1868.1, 2008.

European Centre for Medium-Range Weather Forecasts: ERAInterim Project, doi:10.5065/D6CR5RD9, 2009.

Foelsche, U., Borsche, M., Steiner, A. K., Gobiet, A., Pirscher, B., Kirchengast, G., Wickert, J., and Schmidt, T.: Observing upper troposphere-lower stratosphere climate with radio occultation data from the CHAMP satellite, Clim. Dynam., 31, 49-65, doi:10.1007/s00382-007-0337-7, 2008.

Foelsche, U., Pirscher, B., Borsche, M., Kirchengast, G., and Wickert, J.: Assessing the climate monitoring utility of radio occultation data: From CHAMP to FORMOSAT3/COSMIC, Terr. Atmos. Ocean. Sci., 20, 155-170, doi:10.3319/TAO.2008.01.14.01(F3C), 2009.

Hajj, G. A., Kursinski, E. R., Romans, L. J., Bertiger, W. I., and Leroy, S. S.: A technical description of atmospheric sounding by GPS occultation, J. Atmos. Sol.-Terr. Phy., 64, 451-469, doi:10.1016/S1364-6826(01)00114-6, 2002.

Ho, S.-P., Kirchengast, G., Leroy, S., Wickert, J., Mannucci, A. J., Steiner, A. K., Hunt, D., Schreiner, W., Sokolovskiy, S., Ao, C., Borsche, M., von Engeln, A., Foelsche, U., Heise, S., Iijima, B., Kuo, Y.-H., Kursinski, E. R., Pirscher, B., Ringer, M., Rocken, C., and Schmidt, T.: Estimating the uncertainty of using GPS radio occultation data for climate monitoring: Intercomparison of CHAMP refractivity climate records from 2002 to 2006 from different data centers, J. Geophys. Res., 114, doi:10.1029/2009JD011969, 2009.

Ho, S.-P., Zhou, X., Kuo, Y.-H., Hunt, D., and Wang, J.-H.: Global evaluation of radiosonde water vapor systematic biases using GPS radio occultation from COSMIC and ECMWF analysis, Remote Sensing, 2, 1320-1330, doi:10.3390/RS2051320, 2010.

Ho, S.-P., Hunt, D., Steiner, A. K., Mannucci, A. J., Kirchengast, G., Gleisner, H., Heise, S., von Engeln, A., Marquardt, C., Sokolovskiy, S., Schreiner, W., Scherllin-Pirscher, B., Ao, C., Wickert, J., Syndergaard, S., Lauritsen, K. B., Leroy, S., Kursinski, E. R., Kuo, Y.-H., Foelsche, U., Schmidt, T., and Gorbunov, M.: Reproducibility of GPS radio occultation data for climate monitoring: Profile-to-profile inter-comparison of CHAMP climate records 2002 to 2008 from six data centers, J. Geophys. Res., 117, D18111, doi:10.1029/2012JD017665, 2012. 
Johnson, R. H., Ciesielski, P. E., and Hart, K. E.: Tropical inversions near the $0^{\circ} \mathrm{C}$ Level, J. Atmos. Sci., 53, 1838-1855, 1996.

Kishore, P., Ratnam, M. V., Namboothiri, S., Velicogna, I., Basha, G., Jiang, J., Igarashi, K., Rao, S., and Sivakumar, V.: Global $\left(50^{\circ} \mathrm{S}-50^{\circ} \mathrm{N}\right)$ distribution of water vapor observed by COSMIC GPS RO: Comparison with GPS radiosonde, NCEP, ERAInterim, and JRA-25 reanalysis data sets, J. Atmos. Sol.-Terr. Phy., 73, 1849-1860, doi:10.1016/j.jastp.2011.04.017, 2011.

Knapp, K. R.: Scientific data stewardship of International Satellite Cloud Climatology Project B1 global geostationary observations, J. Appl. Remote Sens., 2, 023548, doi:10.1117/1.3043461, 2008.

Kuo, Y.-H., Wee, T.-K., Sokolovskiy, S., Rocken, C., Schreiner, W., Hunt, D., and Anthes, R. A.: Inversion and error estimation of GPS radio occultation data, J. Meteorol. Soc. Jpn., 82, 507-531, 2004.

Kursinski, E. R. and Hajj, G. A.: A comparison of water vapor derived from GPS occultations and global weather analyses, J. Geophys. Res., 106, 1113-1138, doi:10.1029/2000JD900421, 2001.

Kursinski, E. R., Hajj, G. A., Schofield, J. T., Linfield, R. P., and Hardy, K. R.: Observing Earth's atmosphere with radio occultation measurements using the Global Positioning System, J. Geophys. Res., 102, 23429-23465, doi:10.1029/97JD01569, 1997.

Leroy, S. S., Dykema, J. A., and Anderson, J. G.: Climate benchmarking using GNSS occultation, in: Atmosphere and Climate: Studies by Occultation Methods, edited by: Foelsche, U., Kirchengast, G., and Steiner, A. K., 287-302, Springer, 2006.

Mapes, B. E. and Zuidema, P.: Radiative-dynamical consequences of dry tongues in the tropical troposphere, J. Atmos. Sci., 53, 620-638, 1996.

Melbourne, W. G., Davis, E. S., Duncan, C. B., Hajj, G. A., Hardy, K. R., Kursinski, E. R., Meehan, T. K., Young, L. E., and Yunck, T. P.: The application of spaceborne GPS to atmospheric limb sounding and global change monitoring, JPL Publication, 147, 94-18, 1994.

Miloshevich, L. M., Vömel, H., Whiteman, D. N., Lesht, B. M., Schmidlin, F. J., and Russo, F.: Absolute accuracy of water vapor measurements from six operational radiosonde types launched during AWEX-G and implications for AIRS validation, J. Geophys. Res., 111, D09S10, doi:10.1029/2005JD006083, 2006.

Murphy, D. M. and Koop, T.: Review of the vapour pressures of ice and supercooled water for atmospheric applications, Q. J. Roy. Meteorol. Soc., 131, 1539-1565, doi:10.1256/qj.04.94, 2005.

Pan, L., Atlas, E., Salawitch, R., Honomichl, S., Bresch, J., Randel, W., Apel, E., Hornbrook, R., Weinheimer, A., Anderson, D., Andrews, S., Baidar, S., Beaton, S., Campos, T., Carpenter, L., Chen, D., Dix, B., Donets, V., Hall, S., Hanisco, T., Homeyer, C., Huey, L., Jensen, J., Kaser, L., Kinnison, D., Koenig, T., Lamarque, J., Liu, C., Luo, J., Luo, Z., Montzka, D., Nicely, J., Pierce, R., Riemer, D., Robinson, T., Romashkin, P., Saiz-Lopez, A., Schauffler, S., Shieh, O., Stell, M., Ullmann, K., Vaughan, G., Volkamer, R., and Wolfe, G.: The Convective Transport of Active Species in the Tropics (CONTRAST) Experiment, B. Am. Meteorol. Soc., 98, 106-128, doi:10.1175/BAMS-D-14$00272.1,2017$.
Parsons, D. B., Redelsperger, J.-L., and Yoneyama, K.: The evolution of the tropical western Pacific atmosphere-ocean system following the arrival of a dry intrusion, Q. J. Roy. Meteorol. Soc., 126, 517-548, doi:10.1002/qj.49712656307, 2000.

Pierrehumbert, R. T.: Thermostats, Radiator Fins, and the Local Runaway Greenhouse, J. Atmos. Sci., 52, 1784-1806, 1995.

Poli, P., Joiner, J., and Kursinski, E.: 1DVAR analysis of temperature and humidity using GPS radio occultation refractivity data, J. Geophys. Res., 107, D20, doi:10.1029/2001JD000935, 2002.

Randel, W. J., Rivoire, L., Pan, L., and Honomichl, S.: Dry layers in the tropical troposphere observed during CONTRAST and global behavior from GFS analyses, J. Geophys. Res., 121, 23, doi:10.1002/2016JD025841, 2016.

Smith, E. and Weintraub, S.: The constants in the equation for atmospheric refractive index at radio frequencies, Proc. IRE, 41, 1035-1037, 1953.

Sokolovskiy, S.: Effect of superrefraction on inversions of radio occultation signals in the lower troposphere, Radio Sci., 38, 3, doi:10.1029/2002RS002728, 2003.

Steiner, A. K., Lackner, B. C., Ladstädter, F., Scherllin-Pirscher, B., Foelsche, U., and Kirchengast, G.: GPS radio occultation for climate monitoring and change detection, Radio Sci., 46, RSOD24, doi:10.1029/2010RS004614, 2011.

Vergados, P., Mannucci, A. J., and Ao, C. O.: Assessing the performance of GPS radio occultation measurements in retrieving tropospheric humidity in cloudiness: A comparison study with radiosondes, ERA-Interim, and AIRS data sets, J. Geophys. Res., 119, 7718-7731, doi:10.1002/2013JD021398, 2014.

Vergados, P., Mannucci, A. J., Ao, C. O., Jiang, J. H., and Su, H.: On the comparisons of tropical relative humidity in the lower and middle troposphere among COSMIC radio occultations and MERRA and ECMWF data sets, Atmos. Meas. Tech., 8, 17891797, doi:10.5194/amt-8-1789-2015, 2015.

Wang, B.-R., Liu, X.-Y., and Wang, J.-K.: Assessment of COSMIC radio occultation retrieval product using global radiosonde data, Atmos. Meas. Tech., 6, 1073-1083, doi:10.5194/amt-6-10732013, 2013.

Ware, R., Exner, M., Gorbunov, M., Hardy, K., Herman, B., Kuo, Y., Meehan, T., Melbourne, W., Rocken, C., Schreiner, W., Sokolovskiy, S., Solheim, F., Zou, X., Anthes, R., Businger, S., and Trenberth, K.: GPS Sounding of the Atmosphere from Low Earth Orbit: Preliminary Results, B. Am. Meteorol. Soc., 77, 1, 1996.

Webster, P. J. and Lukas, R.: TOGA-COARE: The Coupled OceanAtmosphere Response Experiment, B. Am. Meteorol. Soc., 73, 1377-1416, 1992.

Zondlo, M. A., Paige, M. E., Massick, S. M., and Silver, J. A.: Vertical cavity laser hygrometer for the National Science Foundation Gulfstream-V aircraft, J. Geophys. Res., 115, D20309, doi:10.1029/2010JD014445, 2010. 